\title{
KINETIKA REAKSI FERMENTASI ALKOHOL DARI BUAH SALAK
}

\author{
Fatimah, Febrina Lia G, Lina Rahmasari G \\ Departemen Teknik Kimia, Fakultas Teknik, Universitas Sumatera Utara, \\ Jalan Almamater Kampus USU Medan 20155, Indonesia \\ E-mail : lina.rahmasari@yahoo.com
}

\begin{abstract}
Abstrak
Penelitian tentang pembuatan bioetanol dari buah salak yang tidak layak jual telah dilakukan. Buah salak mengandung 16,07\% pati dan 32,96\% glukosa, sehingga buah salak berpotensi untuk dikonversikan menjadi bioetanol dengan cara fermentasi. Penelitian ini bertujuan untuk mempelajari rangkaian kinetika reaksi fermentasi alkohol yaitu kinetika reaksi hidrolisa pati menjadi glukosa dan fermentasi glukosa menjadi alkohol dari buah salak dengan menggunakan Saccharomyces cereviseae. Untuk reaksi hidrolisa pati terdapat dua pengendali kecepatan reaksi yaitu reaksi kimia dan difusi film. Dari hasil penelitian untuk reaksi hidrolisa diperoleh konstanta kecepatan reaksi sebesar $1,41 \times 10^{-11}$ dan konstanta koefisien difusi film sebesar 0,47 $\times 10^{-11}$ sehingga kecepatan reaksi hidrolisa yang terjadi dikendalikan oleh difusi film. Konstanta kecepatan reaksi fermentasi diperoleh sebesar 169,88. Selama proses fermentasi berlangsung konsentrasi pati dan glukosa cenderung menurun terhadap waktu fermentasi dan kadar bioetanol cenderung meningkat terhadap lama waktu fermentasi.
\end{abstract}

Kata Kunci : fermentasi, hidrolisa, bioetanol, kinetika reaksi

\begin{abstract}
Research about bioethanol production from salak that are not marketable has been done. Salak containing 16.07\% starch and $32.96 \%$ glucose, so that salak is potential to be converted into bioethanol by fermentation. This research aimed to study reaction kinetic of alcoholic fermentation that are the reaction kinetic of the hydrolysis of starch to glucose and fermentation of glucose to alcohol from salak by using Saccharomyces cereviseae. Hydrolysis of starch reaction containing two reaction rate controls that are chemical reaction and film diffusion. The results obtained for the hydrolysis reaction that the reacion rate constant is $1,41 \times 10^{-11}$ and the film diffusion coefficient constant is 0,47 $x 10^{-11}$ so the rate of the hydrolysis reaction is controlled by the film diffusion. Reaction rate constant for fermentation is 169,88. During the process of fermentation, the concentration of starch and glucose tended to decreased by time of fermentation and bioethanol concentration tended to increase by time of fermentation.
\end{abstract}

Keywords : fermentation, hydrolysis, bioethanol, reaction kinetics

\section{Pendahuluan}

Bioetanol merupakan bahan bakar alternatif yang diolah dari tumbuhan (biomassa) dengan cara fermentasi. Bioetanol yang diolah dari biomassa mampu menurunkan emisi $\mathrm{CO}_{2}$ hingga $18 \%$. Tumbuhan yang mengandung karbohidrat tinggi berpotensial untuk menghasilkan bioetanol.

Buah salak termasuk jenis buah-buahan yang mengandung glukosa tinggi. Tingginya kandungan glukosa yang terdapat pada buah salak berpotensi untuk dijadikan sebagai sumber pembuatan bioetanol. Selain dari pada itu, buah salak merupakan buah yang dapat tumbuh baik di Indonesia, sehingga ketersediaan bahan baku terjamin. Di Sumatera Utara khususnya di Kabupaten Tapanuli Selatan, buah salak banyak dijumpai. Buah salak yang berasal dari daerah Tapanuli Selatan tersebut mengandung kadar gula dan air yang tinggi sehingga buah tersebut cepat membusuk jika terluka.

Mendrofa menyatakan bahwa produksi buah salak Kabupaten Tapanuli Selatan mencapai 100 ton per hari, dan 5-10\% dari buah salak yang dipanen merupakan buah salak yang tidak layak jual karena kulitnya terbuka ataupun buahnya yang terluka [7].
Melihat kondisi ini, buah salak tidak layak jual tersebut berpotensi dijadikan sebagai bahan baku pembuatan bioetanol. Dengan demikian buah salak yang tidak layak jual tersebut tidak terbuang sia-sia.

\section{Teori}

Fermentasi berasal dari kata latin "fervere" yang berarti mendidih yang menunjukkan adanya aktivitas dari yeast pada ekstrak buah-buahan atau biji-bijian. Sedangkan dalam mikrobiologi industri fermentasi diartikan sebagai suatu proses untuk mengubah bahan baku menjadi suatu produk oleh mikroba. Khamir mampu memfermentasi glukosa, fruktosa dan maltosa menjadi bioetanol namun masing-masing spesies mempunyai kecepatan yang berbeda di dalam menggunakan jenis gula yang ada [10].

Pada fermentasi buah salak terjadi perubahan pati menjadi glukosa dan glukosa menjadi bioetanol. Reaksi hidrosis pati berlangsung mengikuti persamaan reaksi berikut [1]:
$\left(\mathrm{C}_{6} \mathrm{H}_{10} \mathrm{O}_{5}\right) \mathrm{n}+\mathrm{nH}_{2} \mathrm{O} \longrightarrow \mathrm{n}\left(\mathrm{C}_{6} \mathrm{H}_{2} \mathrm{O}_{6}\right)$
pati air glukosa 
Reaksi fermentasi glukosa menjadi bioetanol berlangsung mengikuti persamaan reaksi berikut [5] : $\underset{\text { glukosa }}{\mathrm{C}_{6} \mathrm{H}_{12} \mathrm{O}_{6}} \stackrel{\text { Saccharomyces cereviseae }}{\longrightarrow} \underset{\text { etanol }}{2 \mathrm{C}_{2} \mathrm{H}_{5} \mathrm{OH}+2 \mathrm{CO}_{2}}$

Fermentasi bioetanol dipengaruhi oleh faktor-faktor antara lain: $[3,8]$

a. Substrat

Pada umumnya bahan dasar yang mengandung senyawa organik terutama glukosa dan pati dapat digunakan sebagai substrat dalam proses fermentasi bioetanol.

b. Suhu

Suhu optimum bagi pertumbuhan Saccharomyces cereviseae dan aktivitasinya adalah $25-35^{\circ} \mathrm{C}$. Suhu memegang peranan penting, karena secara langsung dapat mempengaruhi aktivitas Saccharomyces cereviseae dan secara tidak langsung akan mempengaruhi kadar bioetanol yang dihasilkan.

c. Nutrisi

Selain sumber karbon, Saccharomyces cereviseae juga memerlukan sumber nitrogen, vitamin dan mineral dalam pertumbuhannya. Pada umumnya sebagian besar Saccharomyces cereviseae memerlukan vitamin seperti biotin dan thiamin yang diperlukan untuk pertumbuhannya. Beberapa mineral juga harus ada untuk pertumbuhan Saccharomyces cereviseae seperti phospat, kalium, sulfur, dan sejumlah kecil senyawa besi dan tembaga.

d. $\mathrm{pH}$

$\mathrm{pH}$ pada proses fermentasi merupakan salah satu faktor yang mempengaruhi kehidupan Saccharomyces cereviseae. Saccharomyces cereviseae dapat tumbuh dengan baik pada kondisi $\mathrm{pH} 4-6$.

e. Konsentrasi substrat

Konsentrasi substrat yang terlalu sedikit akan mengakibatkan produktivitas menurun karena menjadi lelah dan keadaan ini memperbesar terjadinya kontaminasi. Peningkatan konsentrasi substrat akan mempercepat terjadinya fermentasi terutama bila digunakan substrat berkadar tinggi. Tetapi jika konsentrasi substrat berlebihan akan mengakibatkan hilangnya kemampuan bakteri untuk hidup sehingga tingkat kematian bakteri sangat tinggi.

f. Waktu fermentasi

Waktu fermentasi yang biasa dilakukan 3-14 hari. Jika waktunya terlalu cepat Saccharomyces cereviseae masih dalam masa pertumbuhan sehingga alkohol yang dihasilkan dalam jumlah sedikit dan jika terlalu lama Saccharomyces cereviseae akan mati maka alkohol yang dihasilkan tidak maksimal.

\section{Metodologi Penelitian}

Buah salak yang digunakan adalah buah salak produksi Kabupaten Tapanuli Selatan yang tidak layak jual. Buah salak yang tidak layak jual dihancurkan dan dibuat menjadi jus dan kemudian disterilkan. Jus salak yang telah steril kemudian di fermentasikan pada suhu ruangan $\left(30^{\circ} \mathrm{C}\right)$ selama $346 \mathrm{jam}$.
Parameter yang diamati antara lain kadar pati, glukosa, dan etanol. Untuk analisa pati dan glukosa metode yang digunakan adalah metode Luff Schoorl, dan untuk analisa kadar etanol metode yang digunakan adalah metode berat jenis dan penggunaan Gas Chromatography (GC).

Data hasil analisa yang diperoleh selanjutnya digunakan untuk menentukan kinetika reaksi fermentasi. Adapun penentuan kinetika reaksi hidrolisis pati menjadi glukosa dengan menggunakan metode Shrinking Core dan penentuan kinetika reaksi fermentasi menggunakan persamaan Michaelis Menten.

\section{Hasil dan Pembahasan}

Hasil penelitian yang diperoleh mencakup tentang hubungan antara kadar pati, kadar glukosa dan kadar alkohol terhadap waktu fermentasi. Penurunan kadar pati dan serta peningkatan kadar alkohol dipaparkan dalam Tabel 1.

Tabel 1. Hasil Analisa Kadar Pati, Glukosa dan Alkohol Selama 346 jam

\begin{tabular}{|c|c|c|c|}
\hline jam ke- & pati & glukosa & alkohol \\
\hline 0 & 16,07 & 32,96 & 0,00 \\
\hline 24 & 12,69 & 32,03 & 1,24 \\
\hline 48 & 12,36 & 31,10 & 1,93 \\
\hline 72 & 12,10 & 29,09 & 2,96 \\
\hline 96 & 11,69 & 27,25 & 3,25 \\
\hline 120 & 11,66 & 25,75 & 3,41 \\
\hline 144 & 11,31 & 25,15 & 4,22 \\
\hline 168 & 11,17 & 24,28 & 5,07 \\
\hline 192 & 10,89 & 23,55 & 5,89 \\
\hline 226 & 10,76 & 23,26 & 6,36 \\
\hline 250 & 10,63 & 22,83 & 6,89 \\
\hline 274 & 10,49 & 22,10 & 7,12 \\
\hline 298 & 10,29 & 20,94 & 6,91 \\
\hline 322 & 10,28 & 20,65 & 6,47 \\
\hline 346 & 10,28 & 19,95 & 6,24 \\
\hline
\end{tabular}

Trend penurunan kadar pati dan glukosa serta peningkatan kadar alkohol dapat dilihat lebih jelas pada Gambar 1.

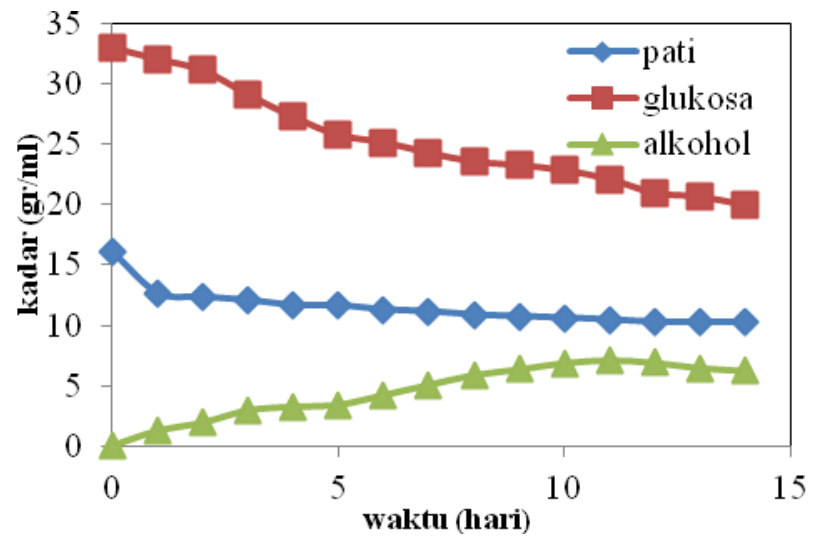

Gambar 1. Hubungan Antara Kadar Pati, Glukosa dan Alkohol terhadap Waktu Fermentasi 
Penurunan Kadar Pati dan Glukosa terhadap Waktu Fermentasi

Gambar 1 menunjukkan bahwa penurunan kadar pati yang signifikan sampai hari ke - 3, dan pada harihari selanjutnya terlihat hampir konstan. Menurut hasil penelitian yang dilakukan oleh Omemu et al pada tahun 2005, penurunan kadar pati yang optimum adalah selama 72 jam [9]. Gambar 1 juga menunjukkan penurunan kadar glukosa selama proses fermentasi berlangsung.

Kadar pati semakin berkurang seiring dengan lama waktu fermentasi. Penurunan kadar pati ini terjadi karena selama proses fermentasi terjadi pemecahan komponen-komponen pati menjadi lebih sederhana yang dilakukan oleh mikroorganisme dalam usahanya memperoleh energi untuk pertumbuhan dan aktivitasnya.

Penurunan kadar glukosa menunjukkan adanya aktivitas fermentasi oleh Saccharomyces cerevisae. Ketersediaan glukosa yang besar pada fermentasi hari ke-0 merupakan sumber nutrisi dan energi bagi $S$. cerevisae. Konsumsi glukosa oleh $S$. cerevisae mengakibatkan menurunnya glukosa pada fermentasi hari berikutnya [2].

\section{Peningkatan Kadar Alkohol terhadap Waktu Fermentasi}

Gambar 1 dapat dilihat bahwa selama proses fermentasi berlangsung kadar etanol cenderung meningkat. Peningkatan kadar etanol merupakan hasil aktivitas yang dilakukan $S$. cerevisae dengan merubah glukosa menjadi etanol.

Penentuan Kinetika Hidrolisis Pati Menjadi Glukosa

Untuk menentukan kinetika reaksi hidrolisis digunakan metode Shrinking Core. Adapun langkah untuk mendapatkan nilai konstanta kecepatan reaksi hidrolisis pati adalah sebagai betikut :

- Menentukan konversi pati menjadi glukosa

- Menentukan waktu tinggal

- Menentukan nilai konstanta kecepatan reaksi

Reaksi hidrolisis pati mengikuti persamaan reaksi berikut:

$$
\underset{\text { air }}{\mathrm{nH}_{2} \mathrm{O}}+\underset{\text { pati }}{\left(\mathrm{C}_{6} \mathrm{H}_{10} \mathrm{O}_{5}\right) \mathrm{n}} \underset{\text { glukosa }}{\longrightarrow} \underset{\left(\mathrm{C}_{6} \mathrm{H}_{2} \mathrm{O}_{6}\right)}{\longrightarrow}
$$

\section{- Penentuan Konversi Pati menjadi Glukosa}

Selama proses hidrolisis pati terkonversi menjadi glukosa. Perhitungan nilai konversi menggunakan persamaan [6] :

$$
\begin{aligned}
& C_{B}=C_{B_{O}}\left(1-X_{B}\right) \\
& X_{B}=1-\frac{C_{B}}{C_{B_{O}}}
\end{aligned}
$$

keerangan : $\mathrm{X}_{\mathrm{B}}=$ konversi pati

$$
\mathrm{C}_{\mathrm{Bo}}=\text { konsentrasi awal pati }=16,07 \%
$$

$\mathrm{C}_{\mathrm{B}}=$ konsentrasi pati pada waktu $\mathrm{t}$

Dengan menggunakan data hasil analisa kadar pati maka diperoleh nilai konversi yang ditampilkan pada Tabel 2 berikut.

Tabel 2. Konversi Pati

\begin{tabular}{|c|c|c|}
\hline jam ke- & $\mathrm{C}_{\mathrm{B}}$ & $\mathrm{X}_{\mathrm{B}}$ \\
\hline 0 & 16,07 & 0 \\
\hline 24 & 12,69 & 0,2103 \\
\hline 48 & 12,36 & 0,2309 \\
\hline 72 & 12,1 & 0,2470 \\
\hline 96 & 11,69 & 0,2726 \\
\hline 120 & 11,66 & 0,2744 \\
\hline 144 & 11,31 & 0,2962 \\
\hline 168 & 11,17 & 0,3049 \\
\hline 192 & 10,89 & 0,3223 \\
\hline 226 & 10,76 & 0,3304 \\
\hline 250 & 10,63 & 0,3385 \\
\hline 274 & 10,49 & 0,3472 \\
\hline 298 & 10,29 & 0,3597 \\
\hline 322 & 10,28 & 0,3603 \\
\hline 346 & 10,28 & 0,3603 \\
\hline
\end{tabular}

Hasil perhitungan pada Tabel 2 untuk kemudian digunakan untuk menentukan nilai waktu tinggal.

\section{- Penentuan Waktu Tinggal ( $\pi$ )}

Untuk menentukan waktu tinggal dapat digunakan persamaan [4] :

$$
\frac{5}{\mathrm{t}}=\left[1-\left(1-X_{B}\right)\right]^{1 / a}
$$

Sehingga dari persamaan tersebut dapat dibuat grafik hubungan waktu vs $\left[1-\left(1-\mathrm{X}_{\mathrm{B}}\right)\right]^{1 / 3}$

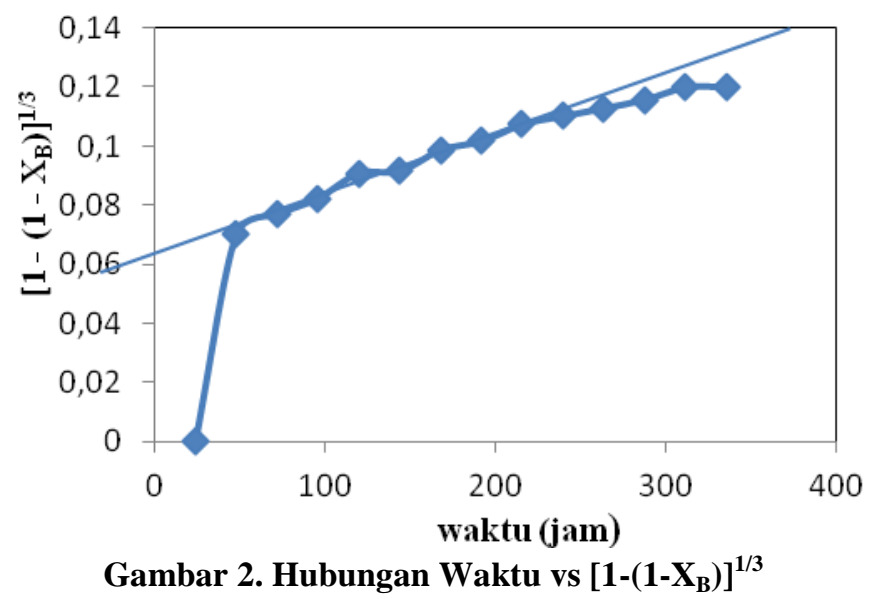

Dari Gambar 2 diperoleh slope $=0,0002$. Slope merupakan $\frac{1}{\pi}$, dengan demikian diperoleh persamaan y $=0,0002 \mathrm{x}$ dan $\tau=4722,6$ jam. Nilai $\tau$ ini kemudian digunakan untuk menentukan konstanta kecepatan reaksi hidrolisis pati.

- Penentuan Konstanta Kecepatan Reaksi

Kecepatan reaksi hidrolisis dikendalikan oleh 2 konstanta, yaitu konstanta kecepatan reaksi yang 
dikendalikan reaksi kimia $\left(\mathrm{K}_{\mathrm{s}}\right)$ dan konstanta koefisien difusi film (D).

Untuk reaksi kimia sebagai pengendali reaksi maka digunakan persamaan :

$$
\begin{aligned}
& \tau=\frac{P_{n} \mathbb{R}}{b K_{2} C_{A I}} \\
& \mathrm{~K}_{\mathrm{S}}=\frac{\mathrm{P}_{\mathrm{a}} \mathrm{R}}{\mathrm{b} \pi \mathrm{C}_{\mathrm{AI}}}
\end{aligned}
$$

Untuk difusi film gas sebagai pengendali reaksi, maka digunakan persamaan :

$$
\mathrm{D}=\frac{\mathrm{P}_{\mathrm{g}} \mathbb{R}}{\mathrm{Sb} \pi \mathrm{C}_{\mathrm{BI}}}
$$

Dimana diketahui :

$$
\begin{array}{ll}
\rho_{\mathrm{B}}=\text { densitas pati } & =0,1597 \mathrm{gr} / \mathrm{ml} \\
\mathrm{R}=\text { jari-jari partikel } & =0,01065 \mathrm{~cm} \\
\mathrm{~b} \quad=\text { derajat polimerisasi pati } & =50000 \\
\mathrm{C}_{\mathrm{AI}}=\text { konsentrasi air } & =1-\left(\mathrm{C}_{\text {pati }}+\mathrm{C}_{\text {glukosa }}\right) \\
& =0,5097
\end{array}
$$

Sehingga diperoleh konstanta kecepatan reaksi, Ks $=1,41 \times 10^{-11}$ dan konstanta koefisien difusi film, $\mathrm{D}=$ $0,47 \times 10^{-11}$. Dari hasil perhitungan yang diperoleh dapat diketahui bahwa reaksi hidrolisis dikendalikan oleh difusi film.

Penentuan Kinetika Fermentasi Glukosa Menjadi Etanol

$$
\underset{\text { glukosa }}{\mathrm{C}_{6} \mathrm{H}_{12} \mathrm{O}_{6}} \stackrel{\text { Saccharomyces cereviseae }}{\longrightarrow} \underset{\text { etanol }}{2 \mathrm{C}_{2} \mathrm{H}_{5} \mathrm{OH}+2 \mathrm{CO}_{2}}
$$

Kecepatan pembentukan poduk dihitung dengan menggunkan persamaan berikut :

$$
\mathrm{V}=\frac{\mathrm{d}[\mathrm{P}]}{\mathrm{t}}
$$

Tabel 3. Kadar glukosa dan alkohol disubstitusikan

\begin{tabular}{|c|c|c|c|c|c|}
\hline $\mathbf{t}$ & {$[\mathbf{S}]$} & $\mathbf{1} /[\mathbf{S}]$ & {$[\mathbf{P}]$} & $\mathbf{V}$ & $\mathbf{1 / V}$ \\
\hline 24 & 32,03 & 0,031 & 1,24 & 0,0517 & 19,35484 \\
\hline 48 & 31,1 & 0,032 & 1,93 & 0,0402 & 24,87047 \\
\hline 72 & 29,085 & 0,034 & 2,96 & 0,0411 & 24,32432 \\
\hline 96 & 27,25 & 0,037 & 3,25 & 0,0339 & 29,53846 \\
\hline 120 & 25,75 & 0,039 & 3,41 & 0,0284 & 35,19062 \\
\hline 144 & 25,15 & 0,04 & 4,22 & 0,0293 & 34,12322 \\
\hline 168 & 24,275 & 0,041 & 5,07 & 0,0302 & 33,13609 \\
\hline 192 & 23,55 & 0,042 & 5,89 & 0,0307 & 32,59762 \\
\hline 216 & 23,26 & 0,043 & 6,36 & 0,0294 & 33,96226 \\
\hline 240 & 22,825 & 0,044 & 6,89 & 0,0287 & 34,83309 \\
\hline 264 & 22,1 & 0,045 & 7,12 & 0,027 & 37,07865 \\
\hline 288 & 20,94 & 0,048 & 6,91 & 0,024 & 41,67873 \\
\hline 312 & 20,65 & 0,048 & 6,47 & 0,0207 & 48,22257 \\
\hline 336 & 19,95 & 0,05 & 6,24 & 0,0186 & 53,84615 \\
\hline
\end{tabular}

\section{Keterangan:}

$\mathrm{t} \quad=$ waktu fermentasi (jam)

$[\mathrm{S}]=$ konsentrasi substrat $/$ glukosa $(\mathrm{gr} / \mathrm{ml})$

$[\mathrm{P}]=$ konsentrasi produk/alkohol $(\mathrm{gr} / \mathrm{ml})$

$\mathrm{V}=$ kecepatan reaksi $(\mathrm{gr} / \mathrm{ml} . j \mathrm{~m})$
Dari tabel 3 dapat dibuat hubungan antara 1/[S] dan 1/V sebagai berikut:

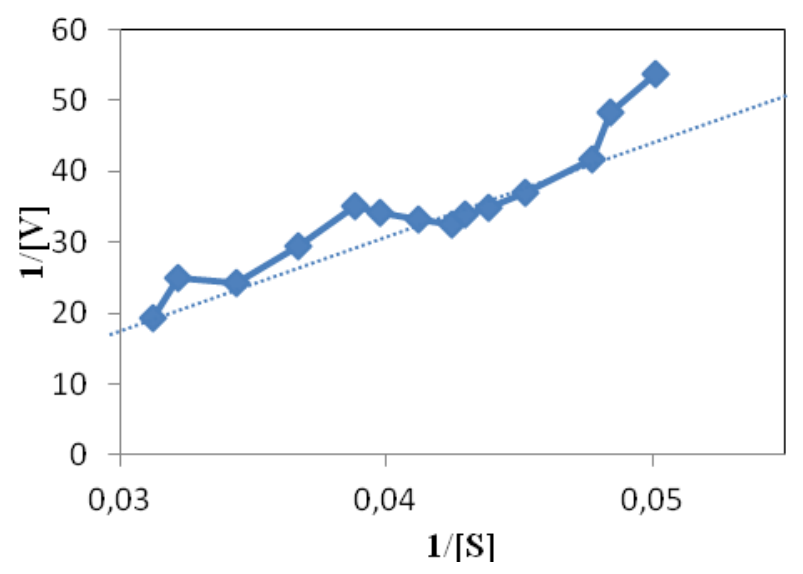

Gambar 3. Hubungan Antara 1/[S] vs 1/V

Grafik ini kemudian didekati dengan persamaan linier sebagai berikut :

$$
\frac{1}{\mathrm{~V}}=\frac{1}{\mathrm{~V}_{\text {maks }}}+\left\{\frac{\mathrm{K}_{\mathrm{m}}}{\mathrm{V}_{\mathrm{maks}}}\right\} \frac{1}{[\mathrm{~S}]}
$$

Sehingga diperoleh:

Intercept $=10,1$

Slope $=1715,79620$

$1 / \mathrm{V}_{\text {maks }}=$ intercept

$\mathrm{V}_{\text {maks }}=0.099 \mathrm{gr} / \mathrm{ml} . \mathrm{jam}$

$\frac{\mathrm{K}_{\mathrm{m}}}{\mathrm{V}_{\text {maks }}}=$ slope

$\frac{\mathrm{K}_{\mathrm{m}}}{0,099}=1715,79620$

$\mathrm{K}_{\mathrm{m}}=169.88 \mathrm{gr} / \mathrm{ml}$

Keterangan:

$\mathrm{V}_{\text {maks }}=$ kecepatan reaksi maksimum (gr/ml.jam)

$\mathrm{K}_{\mathrm{m}} \quad=$ konstanta Michaelis Menten $(\mathrm{gr} / \mathrm{ml})$

\section{Kesimpulan}

Kadar pati dan glukosa pada sampel masingmasing adalah $16,07 \%$ dan $32,96 \%$. Kadar pati dan glukosa cenderung menurun selama proses fermentasi, berbanding terbalik dengan kadar etanol yang cenderung meningkat. Terdapat 2 konstanta yang mempengaruhi laju reaksi hidrolisis pati menjadi glukosa yaitu: Konstanta kecepatan reaksi $\left(\mathrm{K}_{\mathrm{s}}\right)=$ $1,41 \times 10^{-11}$ Konstanta koefisien difusi film $(\mathrm{D})=0,47 \mathrm{x}$ $10^{-11}$. Sehingga pengendali reaksi hidrolisis adalah difusi film. Dari penentuan kinetika fermentasi glukosa menjadi etanol diperoleh: Kecepatan reaksi maksimum $\left(\mathrm{V}_{\text {maks }}\right)=0,099 \mathrm{gr} / \mathrm{ml}$.jam dan konstanta MichaelisMenten $\left(\mathrm{K}_{\mathrm{m}}\right)=169,88 \mathrm{gr} / \mathrm{ml}$

\section{Daftar Pustaka}

[1] Agra, I.B., Warnijati, S, Hidrolisa Pati Ketela Rambat pada Suhu Lebih dari $100^{\circ} \mathrm{C}$, Jurnal 
Forum Teknik, Universitas Gajah Mada, Yogyakarta, 1973.

[2] Ali, W.M, Biokonversi Selulosa Menjadi Sumber Energi Mikrobia, Jakarta, 2008.

[3] Desroir, Norman, Unit Processing Organic Synthesis, Edisi ke-5, McGraw-Hill Book Company, New York, 1988.

[4] Indra B.K dan Retno,D, Kinetika Reaksi Hidrolisa Patidari Kulit Nangka Dengan Katalisator Asam Chlorida Menggunakan Tangki Berpengaduk, Prosiding Seminar Nasional Teknik Kimia Soebardjo Brotohardjono, No. 6, Hal : 1-9, ISSN: 1978-0427, 2010.

[5] Kuswanto, Kapti Rahayu dan Slamet Sudarmaji, Mikrobiologi Pangan, Pusat Antar Universitas Pangan dan Gizi, Universitas Gajah Mada, Yogyakarta , 1989.

[6] Levenspiel, Octave, Chemical Reaction Engineering, Edisi ke-2, John Wiley and Sons, Inc. New York, 1999.

[7] Mendrofa, Gulma. Gulma Mendrofa Sang Pencetus Olahan Salak Dari Tapsel, http://www.medanbisnisonline.com/2009/02/09/gu lma-mendrofasang-pencetus-olahan-salak-daritapsel/, 2009. (Diakses tanggal 23 Desember 2011)

[8] Prescott, S. G dan C. G. Said, Industrial Microbiology, Edisi ke-3, McGraw-Hill Book Company, New York, 1959.

[9] Putri, Lili Suraya Eka, Konversi Pati Ganyong Menjadi Bioethanol Melalui Hodrolisis Asam dan Fermentasi, Universitas Islam Negeri Syarif Hidayatullah, ISSN: 1412-033X, 2008.

[10] Stanbury P.F. dan A. Whitaker, Principles of Fermentation Technology, Pergamon Press, New York, 1984. 